\title{
Modulating effect of ginseng saponins on heterologously expressed HERG currents in Xenopus oocytes ${ }^{1}$
}

Cuk-seong $\mathrm{KIM}^{2}$, Sook-jin $\mathrm{SON}^{2}$, Hyo-shin $\mathrm{KIM}^{2}$, Yong-duk $\mathrm{KIM}^{2}$, Kyu-seung $\mathrm{LEE}^{2}$, Byeong-hwa JEON ${ }^{2}$, Kwang-jin $\mathrm{KIM}^{2}$, Jin-kyu PARK ${ }^{3}$, Jin-bong PARK PA $^{2,4}$

${ }^{2}$ Department of Physiology, College of Medicine, Chungnam National University, Daejeon 301-131, Korea; ${ }^{3}$ Korea Ginseng and Tobacco Research Institute, Daejeon 305-805, Korea

\section{Key words}

Ginseng saponins; Xenopus laevis; potassium channels; action potentials; patch-clamp techniques

\footnotetext{
${ }^{1}$ Project supported by a grant from Korea Research Foundation (2000-002-E00005). ${ }^{4}$ Correspondence to Jin-bong PARK, DVM, PhD.

Phn 82-42-580-8212.

Fax 82-42-545-8440.

E-mail jinbong@cnu.ac.kr
}

Received 2005-01-05

Accepted 2005-03-02

doi: $10.1111 /$ j.1745-7254.2005.00116.x

\begin{abstract}
Aim: To examine the effects of ginseng saponins on the heterologously expressed human ether-a-go-go related gene (HERG) that encodes the rapid component of the delayed rectifier $\mathrm{K}^{+}$channel. Methods: A two-electrode voltage clamp technique was used. HERG currents were recorded in Xenopus oocytes injected with HERG cRNA. Results: Crude saponins of Korean red ginseng (GS) induced a minimal increase of the maximal HERG conductance without changes in the voltage-dependent HERG current activation and inactivation curves. GS, however, decelerated HERG current deactivation in a concentration-dependent manner, which was more noticeable with panaxitriol (PT) than panaxidiol (PD). Consistently, ginseng saponins increased the HERG deactivation time constants with the order of potency of $\mathrm{Rg}_{1}$ (a major component of $\left.\mathrm{PT}\right)>\mathrm{Rf}_{1}>\mathrm{Rb}_{1}$ (a major component of $\mathrm{PD}$ ). Re had little effect on HERG deactivation. During a cardiac action potential, GS increased the outward HERG current. Conclusion: Ginseng saponins enhance HERG currents, which could be in part a possible mechanism of the shortening cardiac action potential of ginseng saponins.
\end{abstract}

\section{Introduction}

Ginseng, the root of Panax ginseng CA Meyer, has been used for more than 2000 years as a general tonic and restorative agent. Ginseng saponins, also called ginsenosides, are one of the main molecular ingredients responsible for the actions of ginseng. Ginseng saponins have beneficial effects on cardiovascular functions ${ }^{[1,2]}$, including the antihypertensive effect ${ }^{[3]}$, the protective effect against ischemia/ reperfusion injury ${ }^{[4]}$, the negative chronotropic and inotropic effects ${ }^{[5]}$, and the antiarrhythmic effect ${ }^{[6,7]}$.

The delayed rectifier $\mathrm{K}^{+}$current is critical for repolarization of cardiac action potential ${ }^{[8]}$, which represents the sum of two components; the rapidly $\left(I_{\mathrm{Kr}}\right)$ and slowly activating components $\left(I_{\mathrm{Ks}}\right)^{[9]}$. The human ether-a-go-go-related gene (HERG) is expressed in the heart of mammalian species including humans ${ }^{[10]}$. It encodes the pore-forming subunit of $I_{\mathrm{Kr}}{ }^{[11,12]}$, which initiates repolarization and terminates the plateau phase of the cardiac action potential. Heterologously expressed HERG currents share pharmacological and biophysical properties with $I_{\mathrm{Kr}}$. It has been shown that channels formed by coexpression of MinK-related protein, MiRP1 and HERG resemble native cardiac $I_{\mathrm{Kr}}$ channels ${ }^{[13]}$. Mutations in the HERG channel gene cause inherited long QT syndrome (LQT), a disorder of cardiac repolarization that predisposes affected individuals to lethal arrhythmias ${ }^{[11,14]}$. Acquired LQT is far more common and is most often caused by commonly used medications blocking cardiac HERG channels $^{[15-18]}$. Thus $I_{\mathrm{Kr}} / \mathrm{HERG}$ is especially relevant to both acquired and inherited forms of $\mathrm{LQT}^{[19,20]}$.

Ginseng saponins decreased the action potential duration of cardiac myocytes ${ }^{[21,22]}$ and showed antiarrhythmic effects ${ }^{[6,7]}$. HERG $/ I_{\mathrm{Kr}}$ has been regarded as a common target of pro- and anti-arrhythmic drugs ${ }^{[19]}$. Therefore, it can be assumed that ginseng saponins may shorten action potential duration and exert antiarrhythmic effects by altering HERG channel activities. To investigate the possibility, we examined the effect of ginseng saponins on the HERG current 
expressed in Xenopus oocytes. We found that ginseng saponins enhanced the HERG current in a concentration- and structure-dependent manner during cardiac action potential.

\section{Materials and methods}

Oocyte preparation Ovarian lobes were excised from anesthetized Xenopus laevis (Xenopus I, Dexter, MI, USA) through a small abdominal incision and were treated with $\mathrm{Ca}^{2+}$-free Barth's solution containing $0.2 \%$ collagenase (type II, Sigma-Aldrich, St Louis, MO, USA) for $1-2 \mathrm{~h}$ and then the remaining inner ovarian epithelium, theca, and follicular cell layers were removed with fine forceps. The composition of $\mathrm{Ca}^{2+}$-free Barth's solution was as follows (mmol/L): $\mathrm{NaCl} 88.7$, $\mathrm{KCl} 1.0, \mathrm{NaHCO}_{3} 2.4, \mathrm{MgSO}_{4} \cdot 7 \mathrm{H}_{2} \mathrm{O}$ 0.8, HEPES 5 ( $\mathrm{pH}=7.5$ ). Only healthy, stage V or VI oocytes were selected for cRNA injection. cRNA of HERG was synthesized from the linearized cDNA using an in vitro transcription kit (Ambion, Austin, TX, USA) and stored at $-80^{\circ} \mathrm{C}$ until used. Denuded oocytes were then injected manually with $50 \mathrm{~nL}$ cRNA $(0.3-1.0 \mathrm{~g} / \mathrm{L})$ using a glass capillary connected with a microdispenser (VWR Scientific, West Chester, PA, USA). For controls, oocytes were either injected with $50 \mathrm{~nL}$ distilled water or left uninjected. After injection, oocytes were cultured at $18^{\circ} \mathrm{C}$ in Barth's solution containing (mmol/L): $\mathrm{NaCl} 88.0, \mathrm{KCl} 1.0$, $\mathrm{NaHCO}_{3} 2.4, \mathrm{MgSO}_{4} \cdot 7 \mathrm{H}_{2} \mathrm{O} \quad 0.8, \mathrm{Ca}\left(\mathrm{NO}_{3}\right)_{2} \cdot 4 \mathrm{H}_{2} \mathrm{O} \quad 0.3, \mathrm{CaCl}_{2}$ 0.4 , HEPES $5(\mathrm{pH}=7.5)$, supplemented with pyruvate $2 \mathrm{mmol} / \mathrm{L}$ and gentamicin sulfate $50 \mathrm{mg} / \mathrm{L}$. The culture medium was changed daily. Currents were recorded 2-7 d after injection.

Whole cell current recording in Xenopus oocytes HERG currents were recorded using a two-electrode voltage-clamp amplifier (OC-725C; Warner Instruments, Hamden, CT, USA) from the oocytes placed in the recording chamber $(2.0 \mathrm{~mL})$ superfused with Oocyte-Ringer solution containing (mmol/L): $\mathrm{NaCl}$ 96.0, $\mathrm{KCl} 2.0, \mathrm{MgCl}_{2} 1.0, \mathrm{CaCl}_{2} \cdot 2 \mathrm{H}_{2} \mathrm{O}$ 1.8, HEPES $5.0(\mathrm{pH}=7.5)$. Stimulation and data acquisition were controlled with Digidata 1200 (Axon Instruments, Union City, CA, USA) and pClamp 6.04 (Axon Instruments). Electrodes were fabricated from glass capillaries containing an inner filament (OD $1.5 \mathrm{~mm}$, ID $1.12 \mathrm{~mm}$; WPI, Sarasota, FL, USA). Electrodes filled with $3 \mathrm{~mol} / \mathrm{L} \mathrm{KCl}$ had a resistance of 1-2 $\mathrm{M} \Omega$ for current-passing electrodes and 2-4 $\mathrm{M} \Omega$ for voltagerecording electrodes.

Data analysis The voltage dependence of HERG current activation was determined for each oocyte by fitting peak values of tail current $\left(I_{\text {tail }}\right)$ versus test potential $\left(V_{\mathrm{t}}\right)$ to Boltzmann's function:

$$
I_{\text {tail }}=\frac{I_{\text {tail }}^{\max }}{1+\exp \left(\frac{V_{1 / 2}-V_{t}}{k}\right)}
$$

where $I_{\text {tail }}{ }^{\max }$ is maximum tail current, $V_{1 / 2}$ is the voltage at which $50 \%$ of the channels are activated, and $k$ is the slope factor. To examine steady-state inactivation, conditioning pulses between -130 and $+20 \mathrm{mV}$ in $10-\mathrm{mV}$ increments for 60 ms were applied after a depolarizing pulse to $+20 \mathrm{mV}$ for 900 $\mathrm{ms}$, followed by a common test pulse to $+20 \mathrm{mV}$. The peak current amplitudes during test pulses were plotted as a function of the previous conditioning pulses. Normalized steadystate inactivation as a function of prepulse of test potential was also fitted to Boltzmann's function. The data were expressed as mean \pm SEM. Statistical analysis were carried out using one-way ANOVA or Student $t$-test when appropriate.

Drugs All drugs except ginsenosides were purchased from Sigma. Lyophilized ginsenosides were kindly donated by Dr PARK of Korean Tobacco and Ginseng Institute.

\section{Results}

The HERG potassium current was recorded by a twoelectrode voltage-clamp from the Xenopus oocyte expression system. Steady-state current was recorded by depolarization to potentials between -60 and $40 \mathrm{mV}$ and the holding potential was maintained at $-80 \mathrm{mV}$ for $4 \mathrm{~s}$. Tail currents were recorded upon repolarization to $-60 \mathrm{mV}$. This voltage protocol was repeated and the amplitude of the current was monitored until no changes in current amplitude could be recorded for $3 \mathrm{~min}$. Figure 1 shows current records obtained in the absence or the presence of $30 \mathrm{mg} / \mathrm{L}$ crude saponin of Korean red ginseng (GS). HERG current amplitudes and deactivation kinetics were changed by bath application of GS, but not by intraoocyte injection of the same concentration of GS (30 mg/L).

Figure 2A shows the effect of extracellular GS (30 mg/L) on the amplitude of steady-state current that was measured at the end of depolarizing pulse and peak tail current. The steady-state current first appears at $-50 \mathrm{mV}$ test potential, and the peak tail current is maximal at $+10 \mathrm{mV}$ test potential. GS $(30 \mathrm{mg} / \mathrm{L})$ induced a minimal increase in steady-state current and peak tail currents (Figure 2A, 2B). The increase of steady-state currents were observed only at more negative membrane voltages than $0 \mathrm{mV}$, where HERG channel inactivation was observed, while the increase of peak tail currents were observed at all tested voltages. Drugs that changed ion channel activities often alter the voltage dependence of channel kinetics. Therefore, we analyzed the 


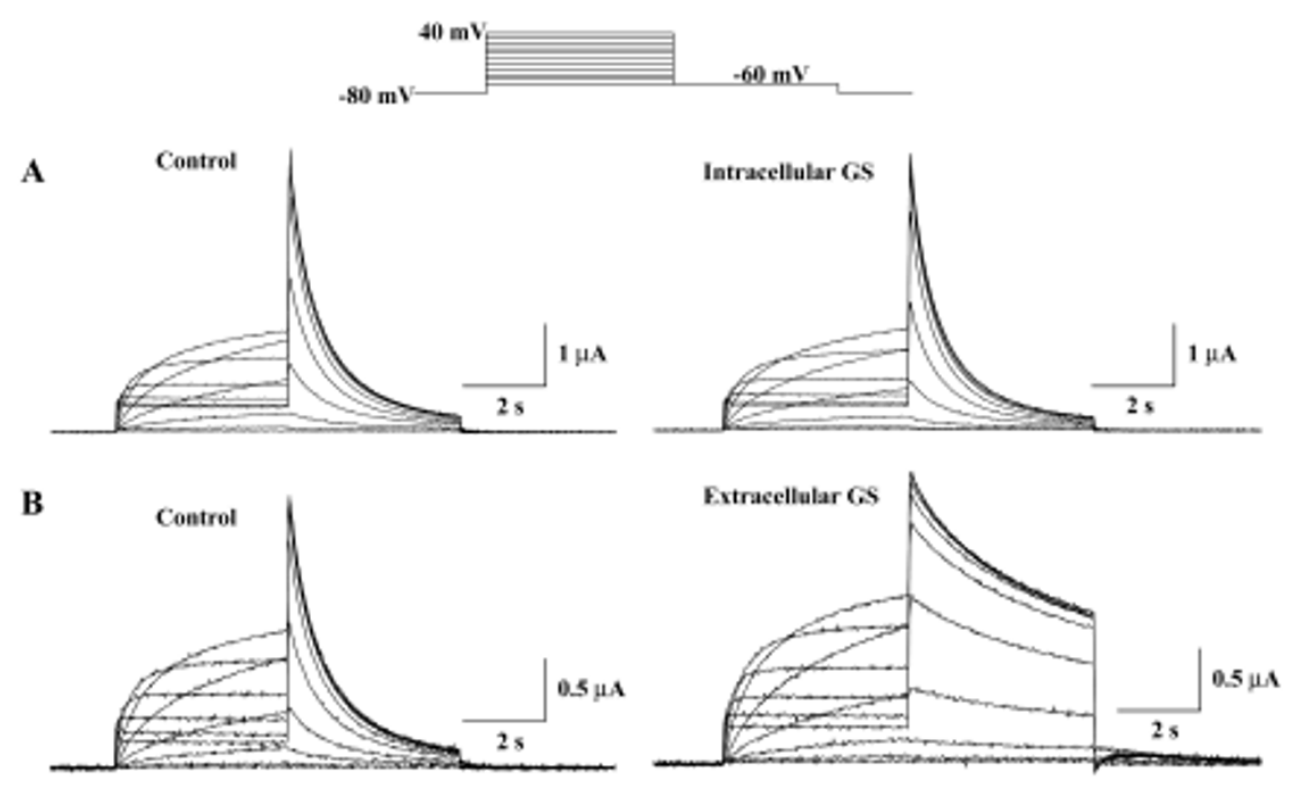

Figure 1. Selective effect of ginseng saponins (GS) on HERG current expressed in Xenopus oocyte. Traces of HERG current were recorded before and after exposure to $30 \mathrm{mg} / \mathrm{L} \mathrm{GS}$ for $10 \mathrm{~min}$ with intra-oocyte injection (A) and bath application (B). Voltage protocol consisted of depolarizing steps from a holding potential of $-80 \mathrm{mV}$ in $10 \mathrm{mV}$ increments from -60 to $+40 \mathrm{mV}$ for $4 \mathrm{~s}$ and repolarizing step to $-60 \mathrm{mV}$ for $6 \mathrm{~s}$ (inset). Steps were repeated at $30 \mathrm{~s}$ intervals.

A

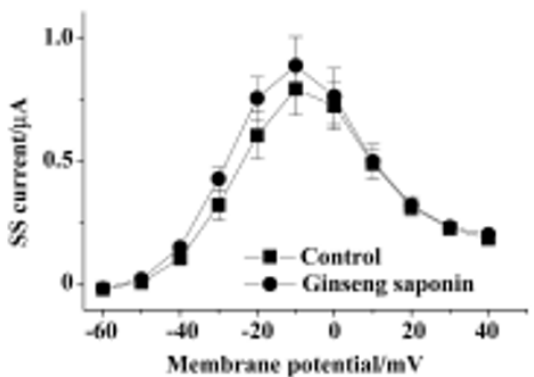

C

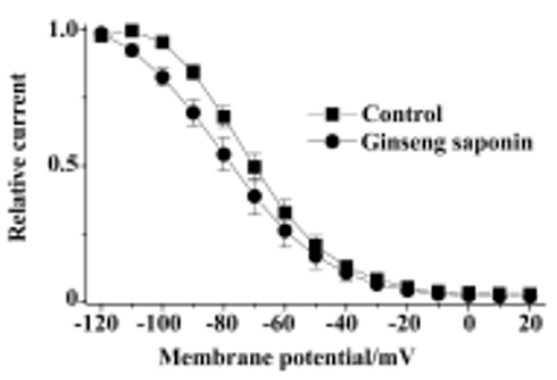

B

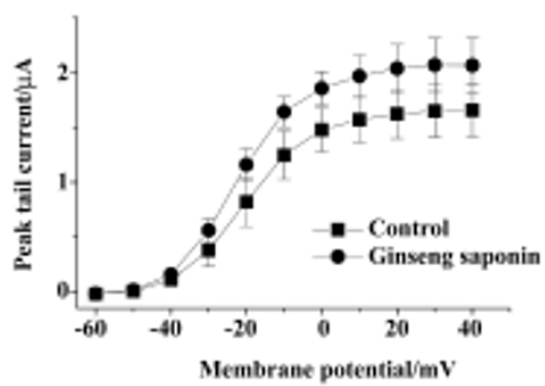

D

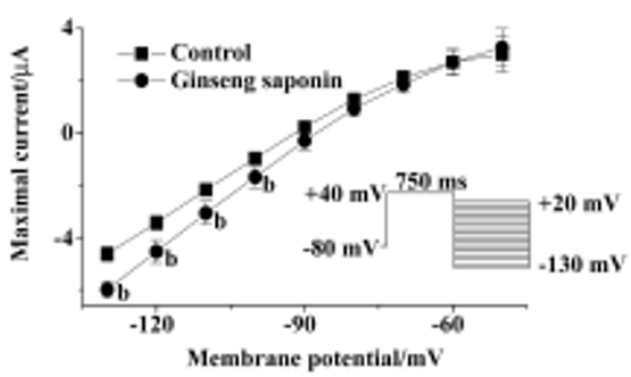

Figure 2. Effect of ginseng saponins (GS) on voltage-dependent kinetics and maximal conductance of HERG current. (A) Current-voltage relation curves were plotted from the current measured at the end of depolarizing test pulse ranging from -60 to $+40 \mathrm{mV}(4 \mathrm{~s}$ in $10 \mathrm{mV}$ increments) from a holding potential of $-80 \mathrm{mV}(n=6)$. (B) Voltage-dependent activation curves plotted from peak tail currents during a repolarizing step to $-60 \mathrm{mV}$ after depolarizing to various voltages $(n=6)$. (C) Steady-state inactivation curves of HERG channels before and after GS exposure. Solid lines indicate the product of the fitted steady-state inactivation curves with Boltzmann's equation on experimental data. (D) Current-voltage plot was obtained from peak tail currents ranging from -130 to $+20 \mathrm{mV}$ following a $750-\mathrm{ms}$ prepulse to $+40 \mathrm{mV}$ from a holding potential of $-80 \mathrm{mV}$. To clarify the change of slope conductance, current amplitudes were plotted between -130 and $-50 \mathrm{mV} . \quad n=6$. Mean $\pm \mathrm{SEM}$. ${ }^{\mathrm{b}} P<0.05$ vs control. 
voltage dependence of activation of the HERG current in the absence or presence of GS. Peak amplitudes of tail currents were plotted as a function of test potential as shown in Figure $2 \mathrm{~B}$, and were fitted with Boltzmann's function. In the control experiment, the activation curve had a mid-point of $-18.1 \pm 2.2 \mathrm{mV}$ and a slope factor of $6.5 \pm 0.2 \mathrm{mV}(n=6)$, which is similar to previous reports ${ }^{[12,23]}$. In the presence of GS (30 $\mu \mathrm{mol} / \mathrm{L})$, a mid-point of $-19.6 \pm 1.9 \mathrm{mV}$ and a slope factor of $7.1 \pm 0.2 \mathrm{mV}(n=6)$, the difference compared with control was not significant.

We also analyzed the steady-state HERG inactivation in the absence and presence of GS. Steady-state inactivation currents were measured with the following protocol: channels were inactivated at a holding potential of $+20 \mathrm{mV}$ before short test pulses. Potentials ranging from $-120 \mathrm{mV}$ to $+20 \mathrm{mV}$ (15 ms, $10 \mathrm{mV}$-increments) were applied to recover the channels from inactivation. Membrane potential returned to a holding potential of $+20 \mathrm{mV}$ after these test pulses evoked large outward inactivating currents. After having obtained a measurement under control conditions, the oocyte was clamped at a holding potential of $-80 \mathrm{mV}$ during a $10-\mathrm{min}$ wash (30 mg/L GS), which was necessary to avoid destruction of the cell. Peak outward current amplitudes after the return to the holding potential were normalized and fitted to Boltzmann's function, which elicited significant left shift in the steady-state inactivation curve ( $n=6$, Figure $2 \mathrm{C})$. In the absence of GS, the inactivation curve had a mid-point of $-69.7 \pm 2.8 \mathrm{mV}$ and a slope factor of $-11.6 \pm 0.8 \mathrm{mV}(n=6)$. These values were $-78.7 \pm 4.5 \mathrm{mV}$ and $-15.3 \pm 0.7 \mathrm{mV}(n=6)$, respectively, in the presence of GS (30 mg/L, $10 \mathrm{~min})$.

To examine whether the increase in HERG current represents the change in HERG conductance, we measured maximal HERG conductance in the absence or presence of GS. For this purpose, we studied the fully activated $I-V$ relationships by applying various test potentials after a depolarizing conditioning pulse (Figure 2D). A conditioning pulse to $+40 \mathrm{mV}$, which induced a full activation, for $750 \mathrm{~ms}$ was applied from a holding potential of $-80 \mathrm{mV}$, followed by test pulses to various potentials between -130 and $+20 \mathrm{mV}$ in $10-\mathrm{mV}$ increments. The amplitude of the current was measured at its peak before the time-dependent change proceeded, and plotted as a function of test potential. GS increased maximal HERG conductance obtained from the slope of the curve (Figure 2D). The slope conductance was obtained from the slope of the $I-V$ curves between -130 and $-110 \mathrm{mV}$. The value of the slope was $0.11 \pm 0.01$ and $0.14 \pm 0.01$ for control and $30 \mathrm{mg} / \mathrm{L} \mathrm{GS}$ (Figure 2D).

To evaluate the most prominent effect of GS on HERG current, decelerating current deactivation, we analyzed the time constant for the deactivation of HERG tail current. For this purpose, we used long hyperpolarizing test pulses following a depolarizing conditioning pulse (Figure 3A). Deactivating currents during test pulses were well fitted to a double-exponential function. GS (3-30 mg/L) increased both fast and slow deactivation time constants of HERG tail current in a concentration-dependent change at all repolarizing tested voltage. The fast deactivation time constants at repolarizing test voltage of $-60 \mathrm{mV}$ were increased from $1.5 \pm$ $0.3 \mathrm{~s}$ of control to $2.2 \pm 1.1,3.2 \pm 1.0,4.1 \pm 1.0$, and $5.1 \pm 1.2 \mathrm{~s}$ by GS 3, 10, 30, and $100 \mathrm{mg} / \mathrm{L}$, respectively (Figure 3B). The slow deactivation time constants at $-60 \mathrm{mV}$ of control were increased from $6.0 \pm 1.4 \mathrm{~s}$ to $7.0 \pm 0.3,9.2 \pm 1.0,11.1 \pm 1.2$, and $17.0 \pm 2.7 \mathrm{~s}$ by GS 3, 10, 30, and $100 \mathrm{mg} / \mathrm{L}$, respectively (Figure 3B).

GS may include many different ginsenosides classified into panaxadiol (PD) and panaxatriol (PT) saponins according to their chemical structures. To know the possible structure-dependent effect of ginsenosides on HERG current, we examined the effect of PD and PT on the deactivation of the HERG tail current. PT evoked more potent deceleration of the HERG deactivation than PD did (Figure 4A). Consistently, deceleration of HERG current was more pronounced by ginsenoside $\mathrm{Rg}_{1}$ and $\mathrm{Rf}_{1}$ the major components of Korean red ginseng (KRG) PT than by ginsenoside $R b_{1}$, the major component of PD (Figure 4B). Interestingly, another PT ginsenoside, Re had little effect on HERG current.

To evaluate the physiological significance of enhancement of HERG by ginsenoside, we examined the effects of GS on repolarizing currents with ramp pulses. In the ramp protocol that involved an initial step depolarization from -80 to $+10 \mathrm{mV}$, followed by a slow ramp $(1.7 \mathrm{~s})$ to $-80 \mathrm{mV}$, GS (10 $\mathrm{mg} / \mathrm{L})$, induced a significant enhancement of the outward current upon slow repolarization (Figure 5).

Finally, we investigated the possible subcellular mechanism of GS effects on HERG currents. We used PTX to test the possible involvement of PTX-sensitive G-protein in GS effects on HERG currents. Pretreatment with PTX (2 mg/L, $16 \mathrm{~h}$ ), however, did not affect HERG current modulation by GS (Figure 6A). To examine whether the intracellular $\mathrm{Ca}^{2+}$ was involved in the modulation of HERG current, we used intracellular $\mathrm{Ca}^{2+}$ buffer, BAPTA. Intraoocyte injection of BAPTA had no effect on GS modulation of the HERG current (Figure 6B).

\section{Discussion}

We have shown that ginsenosides enhance the HERG current expressed in Xenopus oocytes. Ginsenosides are 

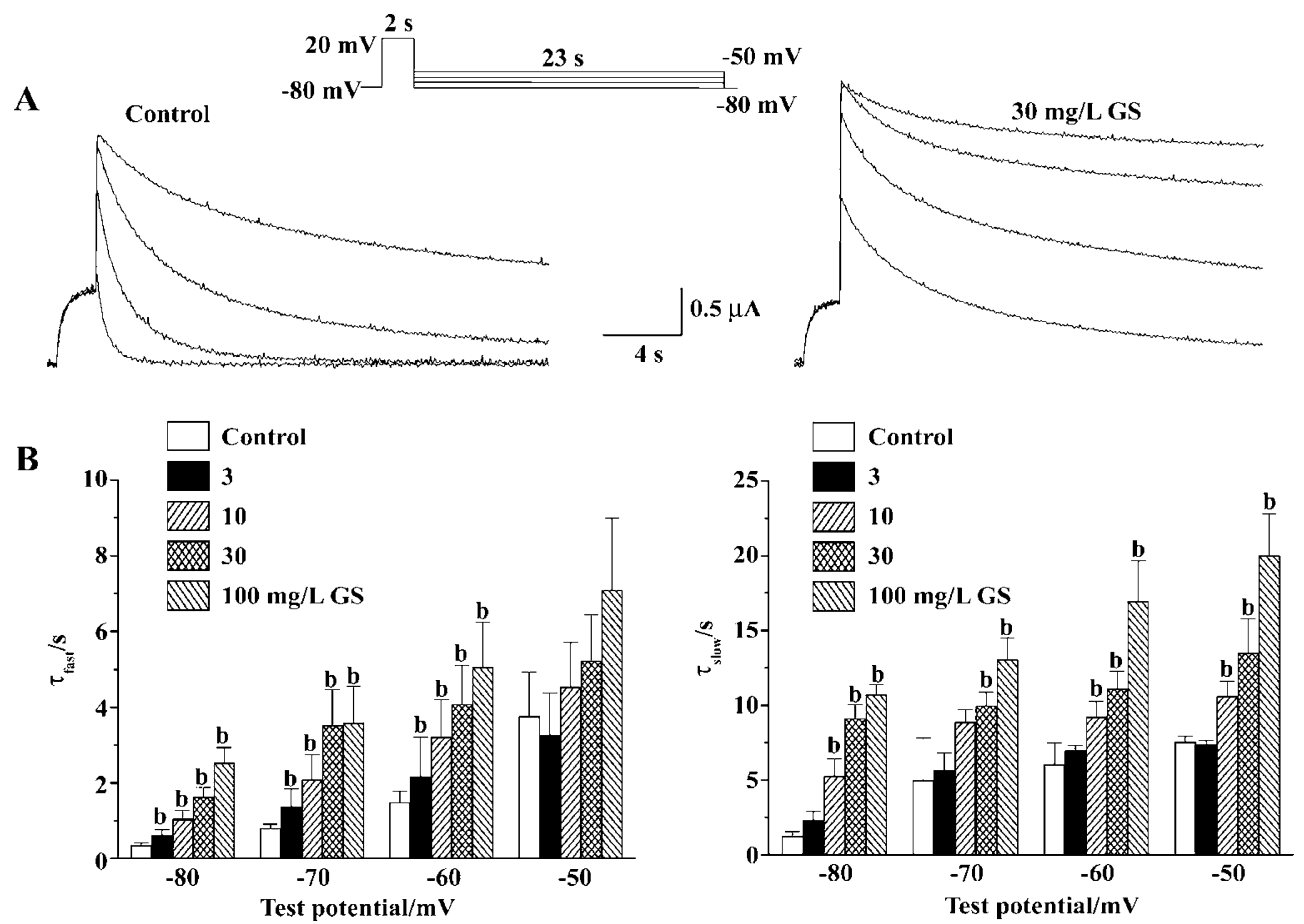

Figure 3. Effects of ginseng saponin on HERG current deactivation. (A) Representative HERG deactivation before and after exposure to GS. Currents were stimulated by a $2 \mathrm{~s}$ prepulse to $+20 \mathrm{mV}$ followed by test pulses ranging from -80 to $-50 \mathrm{mV}$ for $23 \mathrm{~s}$. (B) Effects of different concentrations (3-100 $\mathrm{mg} / \mathrm{L}$ ) of ginseng saponin on HERG deactivation time constants. The deactivation time constants were determined from tail currents recorded during the long-lasting test potentials. Current decay was fitted with a double exponential function. $n=7$ experiments. Mean \pm SEM. ${ }^{\mathrm{b}} \mathrm{P}<0.05$ vs control.

A

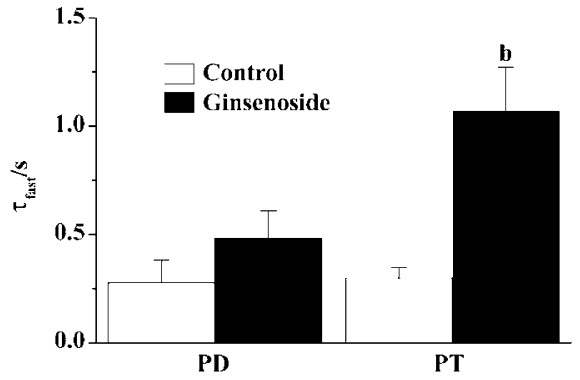

B

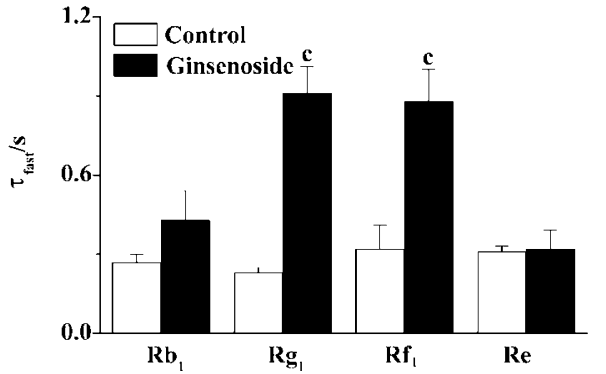

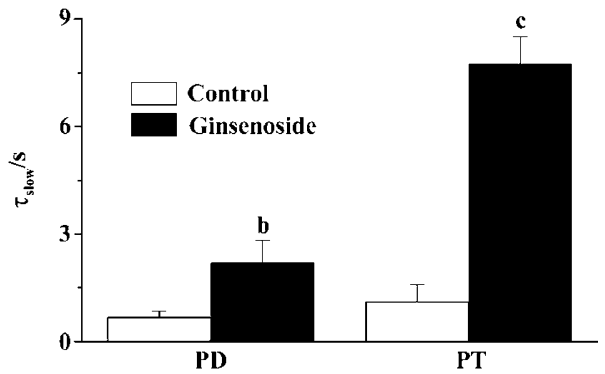

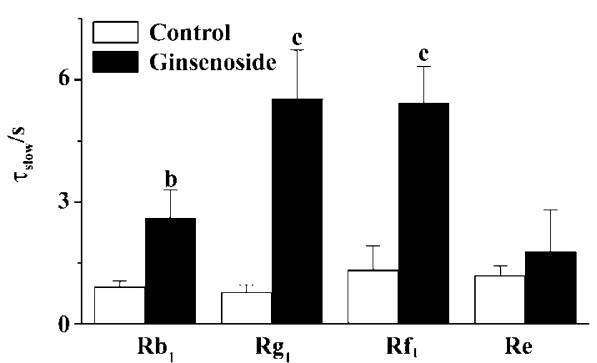

Figure 4. Effects of various ginsenosides on HERG current deactivation. Effects of panaxadiol (PD) and panaxatriol (PT) saponins (A), and ginsenoside $\mathrm{Rg}_{1}, \mathrm{Rf}_{1}, \mathrm{Re}$, and $\mathrm{Rb}$ on HERG current deactivation (B). The pulse protocol is the same as in Figure 3. The fast and slow deactivation time constants of HERG were shown before and after the application of ginsenosides $(30 \mathrm{mg} / \mathrm{L}) . \quad n=4-6$ experiments. Mean \pm SEM. ${ }^{\mathrm{b}} P<0.05$, ${ }^{\mathrm{c}} P<0.01$ vs control. 


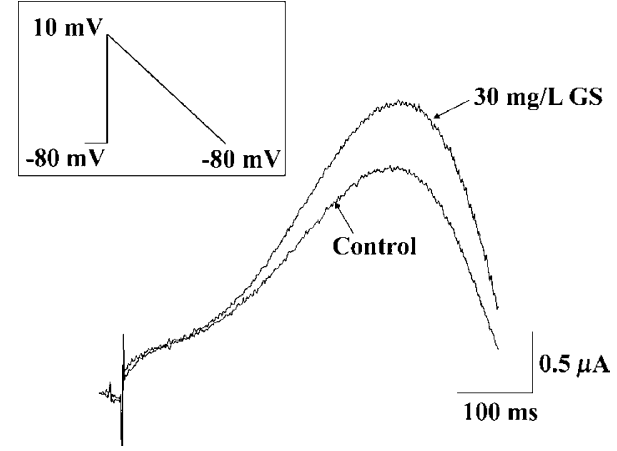

Figure 5. Effects of ginseng saponin (GS) on the HERG current during cardiac action potential. Representative current traces recorded during voltage protocol mimicked cardiac action potential in the absence and presence of GS $(30 \mathrm{mg} / \mathrm{L})$. HERG currents were stimulated by depolarization pulse to $+10 \mathrm{mV}$ following repolarization pulse to $-80 \mathrm{mV}$ for $500 \mathrm{~ms}$ (inset).

known to be effective against cardiac arrhythmias and elicit APD shortening and $I_{\mathrm{K}}$ inhibition $^{[21]}$. It is well known that heterologously expressed HERG currents share pharmacological and biophysical properties with $I_{\mathrm{Kr}}^{[11,12,24,25]}$. The characteristics of the current recorded in the present study correspond to HERG current; slow current activation at negative potentials, large long-lasting tail currents on repolarization, strong inward rectification and sensitivity to class III methanesulfonanilides (data not shown). The present study is the first to characterize the interaction between ginseno- sides and the HERG channels. The major finding of the present study was that ginsenosides enhanced HERG channel activities in a structure- and concentration-dependent manner. Considering all of this, ginsenosides may induce APD shortening partly through enhancement of HERG $/ I_{\mathrm{Kr}}$ as well as $I_{\mathrm{Ks}}{ }^{[21]}$. This finding provides a clearer ionic mechanism of the antiarrhythmic effect of ginsenosides. That is, HERG is another target of ginsenosides.

Mutations in HERG that cause LQT can reduce the amplitude of $I_{\mathrm{Kr}}$ by several different mechanisms. The most common mechanism is a loss of channel function and a dominant negative effect ${ }^{[26]}$. Therefore mutation in HERG also accelerated the rate of channel deactivation and would cause a net reduction in outward current during slow repolarization typical of a cardiac action potential. In the present study, we have shown that GS increased the maximal conductance of HERG potassium channel and it also increased the deactivation time constants of HERG potassium current. Our results, therefore, indicate that the effects of GS on HERG potassium channel may improve the LQT through speed repolarization and shorten the action potential.

To clarify the biophysical mechanism of HERG potentiation by ginsenosides, we analyzed the effect of ginsenosides on HERG current using various pulse protocols. The results suggest that ginsenosides affect preferentially the deactivation of HERG channels with a maximal conductance increase. The rate of recovery from inactivation and the rate

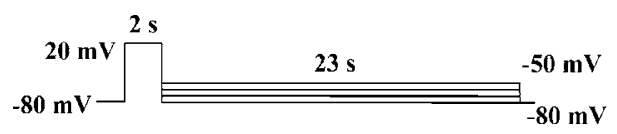

A
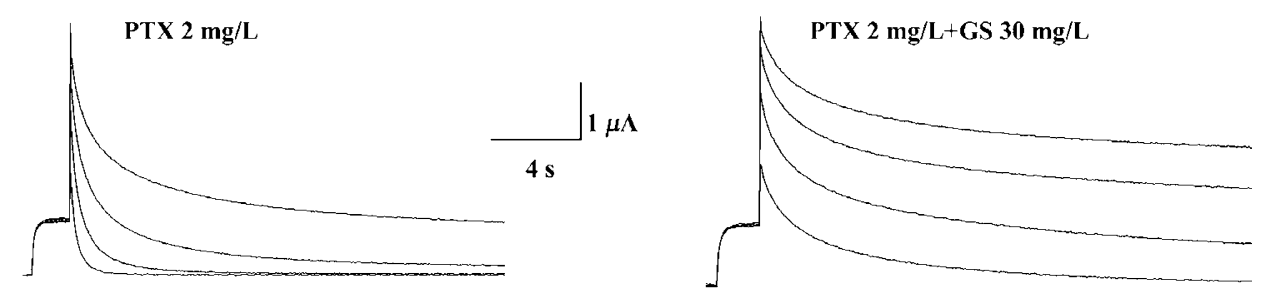

B
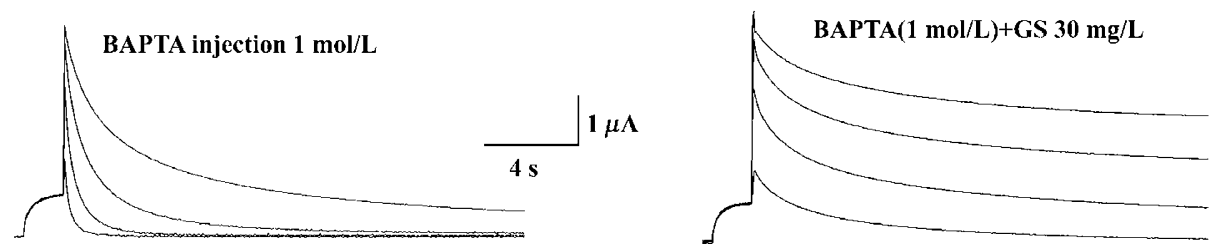

Figure 6. Effect of ginseng saponin (GS) on HERG current in different conditions. Deceleration of HERG current deactivation by GS was not altered by extracellular PTX pretreatment $(2 \mathrm{mg} / \mathrm{L}, 16 \mathrm{~h})(\mathrm{A})$ or by intra-oocyte injection of BAPTA ( $1 \mathrm{mmol} / \mathrm{L})(\mathrm{B})$. Representative currents stimulated by a series of step pulses. The pulse protocol is the same as in Figure 4. 
of deactivation are major HERG channel kinetic factors determining the duration of the action potential ${ }^{[27]}$. HERG modulation is expected to speed repolarization and shorten the action potential, which could decrease the inter-spike interval and accelerate the heart rate.

How might a GS contribute to the enhancement of HERG potassium current? The heart is presented with continually varying cardiovascular demands that require dynamic responses, both inotropic and chronotropic. Most cardiac adaptation that occurs is the result of changes in autonomic/ hormonal stimulation involving G-protein-coupled receptors ${ }^{[28]}$. In a previous study, ginsenosides were shown to increase the $\mathrm{Ca}^{2+}$-activated $\mathrm{Cl}^{-}$current in Xenopus oocytes through a signaling pathway linked to the muscarinic ACh receptor, which involves $\mathrm{G}$ protein-coupled PLC activation and $\mathrm{Ca}^{2+}$ mobilization from $\mathrm{IP}_{3}$-sensitive intracellular store ${ }^{[29]}$. In our experiments, the effects of GS on HERG potassium currents were not blocked by intracellular $\mathrm{Ca}^{2+}$ chelation and intraoocyte injection of BAPTA nor pretreatment with PTX ( $2 \mathrm{mg} / \mathrm{L}, 16 \mathrm{~h}$ ) (Figure 6A, 6B). Therefore, it should be noted that ginsenoside $\mathrm{Rf}$ could regulate GIRK channels with unidentified proteins derived from the rat brain through PTXinsensitive $G$ proteins ${ }^{[30]}$. However, we still cannot exclude the possibility of direct interaction between ginsenosides and HERG channel proteins.

Approximately 30 different ginsenosides have now been isolated and identified from Panax ginseng. Studies have shown that certain ginsenosides are more potent than others ${ }^{[31]}$. It should be noted that ginsenoside Re had no effect on HERG currents, showing the structure-dependence of HERG modulations by ginsenosides. HERG currents were enhanced by PT and PD as well as by ginsenoside $R b_{1}, \mathrm{Rg}_{1}$, and $\mathrm{Rf}$ with different potency. Crude saponin of KRG used in this experiment contained $56.3 \%$ of ginsenosides. Therefore, the effect of KRG-CS on the HERG potassium current was mainly a result of the saponin fraction of KRG.

Synthetic molecules such as fenamates and other openers of the $\mathrm{K}^{+}$channel offer a novel therapeutic approach to stabilizing and controlling cellular function ${ }^{[32]}$. Our results, demonstrate for the first time a link between ginseng saponin and the electrophysiological properties of the HERG channel. The positive regulation by ginseng saponin on HERG and the previously described effects on $I_{\mathrm{Ks}}^{[21,22]}$, suggest a potential role for ginseng saponin in the prevention or treatment of long QT syndrome.

\section{References}

1 Chen X. Cardiovascular protection by ginsenosides and their nitric oxide releasing action. Clin Exp Pharmacol Physiol 1996; 23:
728-32.

2 Zhang JM, Matsuura Y, Sueda T, Orihashi K. Beneficial effects of ginsenosides of stems and leaves on cardiac and coronary vascular functions after 12-hour rat heart preservation. Transplant Proc 1999; 31: 2175-8.

3 Jeon BH, Kim CS, Kim HS, Park JB, Nam KY, Chang SJ. Effect of Korean red ginseng on blood pressure and nitric oxide production. Acta Pharmacol Sin 2000; 21: 1095-100.

4 Zhan Y, Xu XH, Jiang YP. Protective effects of ginsenoside on myocardiac ischemic and reperfusion injuries. J Natl Med J China 1994; 74: 626-8.

5 Wu JX, Chen JX. Negative chronotropic and inotropic effects of Panax notoginseng saponins. Acta Pharmacol Sin 1988; 9: 409-12.

6 Li XJ, Zhang BH. Studies on anti-arrhythmia effects of panaxatriol saponins isolated from Panax notoginseng. Acta Pharm Sin 1988; 23: 168-73.

7 Zhang RB, Li ZY, Shi HY. Cardiac arrhythmia induced by hypothalamic stimulation in cardiac ischemic rabbits and the antiarrhythmic action of Panax ginseng. Acta Pharmacol Sin 1982; 3: 226-30.

8 Carmeliet E. $\mathrm{K}^{+}$channels and control of ventricular repolarization in the heart. Fundam Clin Pharmacol 1993; 7: 19-28

9 Sanguinetti MC, Jurkiewicz NK. Two components of cardiac delayed rectifier $\mathrm{K}^{+}$current. Differential sensitivity to block by class III antiarrhythmic agents. J Gen Physiol 1990; 96: 195-215.

10 Wymore RS, Gintant GA, Wymore RT, Dixon JE, McKinnon D, Cohen IS. Tissue and species distribution of mRNA for the $I_{\mathrm{Kr}}$-like $\mathrm{K}^{+}$ channel, erg. Circ Res 1997; 80: 261-8.

11 Sanguinetti MC, Jiang C, Curran ME, Keating MT. A mechanistic link between an inherited and an acquired cardiac arrhythmia: HERG encodes the $I_{\mathrm{Kr}}$ potassium channel. Cell 1995; 81: 299-307.

12 Wang S, Liu S, Morales MJ, Strauss HC, Rasmusson RL. A quantitative analysis of the activation and inactivation kinetics of HERG ex pressed in Xenopus oocytes. J Physiol 1997; 502: 45-60.

13 Abbott GW, Sesti F, Splawski I, Buck ME, Lehmann MH, Timothy $\mathrm{KW}$, et al. MiRP1 forms $I_{\mathrm{Kr}}$ potassium channels with HERG and is associated with cardiac arrhythmia. Cell 1999; 97: 175-87.

14 Curran ME, Splawski I, Timothy KW, Vincent GM, Green ED, Keating MT. A molecular basis for cardiac arrhythmia: HERG mutations cause long QT syndrome. Cell 1995; 80: 795-803.

15 Suessbrich H, Waldegger S, Lang F, Busch AE. Blockade of HERG channels expressed in Xenopus oocytes by the histamine receptor antagonists terfenadine and astemizole. FEBS Lett 1996; 385: 77-80.

16 Rampe D, Roy ML, Dennis A, Brown AM. A mechanism for the proarrhythmic effects of cisapride (Propulsid): high affinity blockade of the human cardiac potassium channel HERG. FEBS Lett 1997; 417: 28-32.

17 Drolet B, Vincent F, Rail J, Chahine M, Deschenes D, Nadeau S, et al. Thioridazine lengthens repolarization of cardiac ventricular myocytes by blocking the delayed rectifier potassium current. J Pharmacol Exp Ther 1999; 288: 1261-8.

18 Volberg WA, Koci BJ, Su W, Lin J, Zhou J. Blockade of human cardiac potassium channel human ether-a-go-go-related gene (HERG) by macrolide antibiotics. J Pharmacol Exp Ther 2002; 302: 320-7.

19 Mitcheson JS, Chen J, Lin M, Culberson C, Sanguinetti MC. A structural basis for drug-induced long QT syndrome. Proc Natl Acad Sci USA 2000; 97: 12329-33.

20 Tseng GN. $I_{\mathrm{Kr}}$ : the hERG channel. J Mol Cell Cardiol 2001; 33: 
835-49.

21 Bai CX, Sunami A, Namiki T, Sawanobori T, Furukawa T. Electrophysiological effects of ginseng and ginsenoside Re in guinea pig ventricular myocytes. Eur J Pharmacol 2003; 476: 35-44.

22 Bai CX, Takahashi K, Masumiya H, Sawanobori T, Furukawa T. Nitric oxide-dependent modulation of the delayed rectifier $\mathrm{K}^{+}$ current and the L-type $\mathrm{Ca}^{2+}$ current by ginsenoside $\mathrm{Re}$, an ingredient of Panax ginseng, in guinea-pig cardiomyocytes. $\mathrm{Br} \mathrm{J}$ Pharmacol 2004; 142: 567-75.

23 Park JB, Choe H, Lee YK, Ha KC, Rhee KS, Ko JK, et al. Open channel block by KCB-328 [1-(2-amino-4-methanesulfonamidophenoxy)-2[ $N$-(3,4-dimethoxyphenethyl)- $N$-methylamino]ethane hydrochloride] of the heterologously expressed human ether-a-go-go-related gene $\mathrm{K}^{+}$ channels. J Pharmacol Exp Ther 2002; 302: 314-9.

24 Kiehn J, Wible B, Ficker E, Taglialatela M, Brown AM. Cloned human inward rectifier $\mathrm{K}^{+}$channel as a target for class III methanesulfonanilides. Circ Res 1995; 77: 1151-5.

25 Spector PS, Curran ME, Keating MT, Sanguinetti MC. Class III antiarrhythmic drugs block HERG, a human cardiac delayed rectifier $\mathrm{K}^{+}$channel. Open-channel block by methanesulfonanilides. Circ Res 1996; 78: 499-503.

26 Sanguinetti MC. Dysfunction of delayed rectifier potassium chan- nels in an inherited cardiac arrhythmia. Ann N Y Acad Sci 1999; 868: 406-13.

27 Zhou Z, Gong Q, Epstein ML, January CT. HERG channel dysfunction in human long QT syndrome. Intracellular transport and functional defects. J Biol Chem 1998; 273: 21061-6.

28 Bian J, Cui J, McDonald TV. HERG $\mathrm{K}^{+}$channel activity is regulated by changes in phosphatidyl inositol 4,5-bisphosphate. Circ Res 2001; 89: 1168-76.

29 Choi S, Rho SH, Jung SY, Kim SC, Park CS, Nah SY. A novel activation of $\mathrm{Ca}^{2+}$-activated $\mathrm{Cl}^{-}$channel in Xenopus oocytes by Ginseng saponins: evidence for the involvement of phospholipase $\mathrm{C}$ and intracellular $\mathrm{Ca}^{2+}$ mobilization. Br J Pharmacol 2001; 132: $641-8$.

30 Choi S, Jung SY, Ko YS, Koh SR, Rhim H, Nah SY. Functional expression of a novel ginsenoside Rf binding protein from rat brain mRNA in Xenopus laevis oocytes. Mol Pharmacol 2002; 61: 928-35.

31 Nah SY, Park HJ, McCleskey EW. A trace component of ginseng that inhibits $\mathrm{Ca}^{2+}$ channels through a pertussis toxin-sensitive $\mathrm{G}$ protein. Proc Natl Acad Sci USA 1995; 92: 8739-43.

32 Lawson, K. Potassium channel openers as potential therapeutic weapons in ion channel disease. Kidney Int 2000; 57: 838-45. 